\title{
Efficacy of mummy on healing of pressure ulcers: A randomized controlled clinical trial on hospitalized patients in intensive care unit
}

Masoud Moghadari ${ }^{1,2}$, Mozafar Rezvanipour ${ }^{1}$, Mitra Mehrabani ${ }^{3}$, Mehdi Ahmadinejad ${ }^{4}$, Haleh Tajadini ${ }^{1,2}$, Mohammad Hashem Hashempur ${ }^{5,6}$

${ }^{1}$ Neuroscience Research Center, Institute of Neuropharmacology, Kerman University of Medical Sciences, Kerman, Iran

${ }^{2}$ Department of Persian Medicine, School of Persian Medicine, Kerman University of Medical Sciences, Kerman, Iran

${ }^{3}$ Department of Pharmacognosy, Herbal and Traditional Medicines Research Center, Kerman University of Medical Sciences, Kerman, Iran

${ }^{4}$ Kerman University of Medical Sciences, Kerman, Iran

${ }^{5}$ Noncommunicable Diseases Research Center, Fasa University of Medical Sciences, Fasa, Iran

${ }^{6}$ Department of Persian Medicine, School of Medicine, Fasa University of Medical Sciences, Fasa, Iran

\section{Type of article: Original}

\begin{abstract}
Background: Mummy is a mineral substance which according to Persian medicine texts, may be useful in treatment of chronic ulcers.

Objective: The present study was performed with the aim of determining the effect of mummy on healing of pressure in male patients who had been hospitalized due to cerebrospinal injury in the Intensive Care Unit.

Methods: This randomized, placebo-controlled clinical trial was performed on 75 patients who had pressure ulcer at Shahid Bahonar Hospital in Kerman, Iran, from September 2016 to March 2017. The control group received normal saline and routine wound dressing, while the intervention group received mummy water solution $20 \%$ in addition to normal saline and routine wound dressing on a daily basis. Data was recorded based on the PUSH method. In both groups, ulcers were evaluated on days $0,7,14,21$ and 28 for the variables of ulcer surface area, the amount of exudate and type of tissue. Data analysis was done through SPSS 21 and using t-test, Repeated Measure Analysis, Cox Regression and Chi-square.

Results: Both groups showed reduction in the average ulcer surface area (3.26 to 0.53 in the intervention group and 5.1 to 3.46 in the control group), the average exudate amount (1.26 to 0.26 in the intervention group and 1.83 to 1.06 in the control group) and the average tissue score (1.36 to 0.23 in the intervention group and 2.13 to 1.26 in the control group). Over the entire study period, the intervention group showed more acceptable signs of healing compared to the control group $(\mathrm{p}<0.05)$.

Conclusion: The healing process was more prominent in the intervention group than the control group.

Clinical trial registration: The trial was registered at the Iranian Registry of Clinical Trials with registered NO. (IRCT2014042917494N1) (29/04/2014).

Funding: No financial support for the research.

Keywords: Pressure ulcer, Mummy, Intensive care unit
\end{abstract}

\section{Introduction}

A pressure ulcer is the result of applying too much pressure on capillaries $(32 \mathrm{~mm} / \mathrm{Hg})$ over a prolonged period. Risk factors of pressure ulcer are of two types of extrinsic and intrinsic. Intrinsic risk factors include immobility,

\section{Corresponding author:}

Assistant Professor Dr. Haleh Tajadini, Kerman University of Medical Sciences, Kerman, Iran.

Tel.: +989131972312 and +983432102020, Email: dr_haleh@yahoo.com

Received: August 07, 2017, Accepted: November 20, 2017, Published: January 2018

iThenticate screening: October 03, 2017, English editing: December 04, 2017, Quality control: December 09, 2017

This article has been reviewed / commented by four experts

(C) 2018 The Authors. This is an open access article under the terms of the Creative Commons Attribution-NonCommercialNoDerivs License, which permits use and distribution in any medium, provided the original work is properly cited, the use is non-commercial and no modifications or adaptations are made. 
malnutrition, urinary and fecal incontinence, poor blood flow, low blood pressure and aging. Extrinsic factors are humidity, friction, pressure and skin thickness reduction (1). The two factors of immobility and malnutrition are more discussed in ICU patients, and those with cerebrospinal injury, coma, brain vascular events and paralyzed limbs are at higher risk of pressure ulcer. In patients with immobility or poor mobility, urinary or fecal incontinence also increases the risk of this problem (2). In an Uzun et al. study in Turkey (2009), the prevalence of pressure ulcer in the ICU patients of a selected medical center was reported to be $37 \%$ (3). According to the previous studies, $90 \%$ of pressure ulcers have been reported in inferior parts of the body, and of them, $65 \%$ had been in the pelvic and surrounding areas and 30\% in the lower limbs. In ICU, the rate of pressure ulcer has been $36 \%$ in the sacrum, $30 \%$ in the heel and $6 \%$ in the ankle. These studies show that applying too much pressure on skin during long-term bed rest without any position changing is the most important cause of pressure ulcer in immobile patients with cerebrospinal injury. These pressure ulcers increase the length of hospitalization and disease complications and consequently, impose extra costs on both patients and health services. Annual cost of pressure ulcer has been estimated to be 836 million dollars in the USA (4). Hunter et al. have reported mortality rate of $7-8 \%$ in their study patients due to the complications of pressure ulcer (5). In spite of all progresses in treatment and prevention of pressure ulcer, the number of patients with this complication has been increasing, and although various methods such as skin hygiene, sufficient nutrition, frequent change of patient position, avoiding skin damage, different wound dressings, application of honey, using electric voltages such as laser therapy, high $\mathrm{O}_{2}$ pressure and traditional wound dressings are widely used today, still a great number of patients suffer from pressure ulcer (6). According to Persian medicine literature, mummy is a mineral which is effective in healing pressure ulcer (7). Mummy is a Greek term meaning "corpse protector" (hafeze jasad) that is called Mummy in Iran, Shilajit in India and Aragh-ol-jebal in Arabic countries. Mummy is one of the old medicines in Iran and is a black or brown semi-solid substance produced as a result of oxidation of oil hydrocarbons in the fissures of high mountains (8). It is composed of 52 substances including Oxygen, Nitrogen, Sulfur and hydrocarbon. It melts at $100^{\circ} \mathrm{C}$ and its specific gravity is 1.2 . After dissolving it in oil, a soft substance is produced that was rubbed on damaged parts of skin in the past (9). Mummy (shilajit) has been used for the treatment of various diseases over the years. There are several studies about the effects and properties of mummy (shilajit) among new studies. Goel et al. (1990) have conducted a study on antiulcerogenic and anti-inflammatory effects of Shilajit and showed that oral administration of $100 \mathrm{mg} / \mathrm{kg}$ shilajit twice a day decreases gastric ulcer index and increases carbohydrate to protein ratio (10). In an Acharya et al. study (1998), analgesic effect of Shilajit (200mg) has been reported. Moreover, administration of 50-200 mg shilajit twice a day caused significant dose-dependent decrease of peptic ulcer in laboratory mice (11). Rezvanipour et al. have conducted a study on mice and concluded that mummy increases tensile strength of wound ulcers, which can be due to probable beneficial effects of mummy in collagen production and release (12). Despite our comprehensive literature review, we could not find any clinical trial about the effect of mummy on pressure ulcers. Therefore, the present study was performed with the aim of determining the effect of mummy on healing of pressure ulcers in male patients who had been hospitalized in the Intensive Care Unit due to cerebrospinal injuries.

\section{Material and Methods}

\subsection{Study design}

This randomized controlled clinical trial had two parallel arms. It was performed on 75 patients in the intensive care unit (ICU) of Shahid Bahonar Hospital of Kerman, Iran with grade II and III of pressure ulcer. According to similar studies, with respect to the average of the first group (0.79) and the second group (0.9) and the standard deviations of 0.1 and 0.2 and by using sample size formula to compare averages of the two groups, the sample size was calculated to be 30 patients in each group.

\subsection{Ethical considerations}

First, the study details were explained for all patients, and informed written consent was obtained from them before enrollment. All patients were uninformed. In addition, the research protocol was approved in the Medical Ethics Committee of Kerman University of Medical Sciences and the trial protocol was submitted to the Iranian Registry of Clinical Trials (IRCT2014042917494N1) (29/04/2014).

\subsection{Inclusion and exclusion criteria}

Patients over 18 years old with confirmed diagnosis of grade II and III bedsore were included if they had a single ulcer with a diameter less than $15 \mathrm{~cm}$ in its widest part, and given informed written consent for participation in the study. Patients were excluded if they had any type of pathology based on which judgment about the process of wound healing can be a confounding factor (neoplasia, immunologic disorders), renal dysfunction, diabetes, hypertension and infected wound. Therefore, all patients were unconscious and had fecal incontinence. They had 
been hospitalized in ICU for at least one month, and all of them had been transferred to the ICU from the emergency department, ward or operating room. Patients were under mechanical ventilator and received sedative drugs in order to tolerate the instrument.

\subsection{Preparation of Persian Medicine product}

The high quality mummy (lacking any type of waste materials and sand) gathered from the rocks of Khabar Mountain in Baft, Kerman, Iran by professional rock climbers, was purchased, and its quality was confirmed by knowledgeable local residents and pharmaceutical experts. Its saturated solution (20 gr Mummy in $100 \mathrm{ml}$ water) was prepared and sterilized at $115-180^{\circ} \mathrm{C}$, under 0.7 bar pressure for 30 minutes (13). Then it was kept in clean closed dishes until use. After removing it from the dishes, the excess amount was disposed of.

\subsection{Sample size and randomized allocation of patients}

The following formula was used in the present study: $n=2\left(Z_{\alpha / 2}+Z_{\beta}\right)^{2} \sigma^{2}(1=(m-1) \rho) / m^{2}$, where $\alpha=0.05$, 1- $\beta=0.8$, $\mathrm{m}=2$ (the number of measurements for each subject), $\rho=0.05$ (process correlation), $\mathrm{d}=2$ (least significant difference to be detected for recovery of the ulcer) and $\sigma=4.5$ (process variance) were considered. Sample size for each group was determined as at least 35 patients. A total number of 75 patients in ICU were selected through randomized block allocation (with block sizes of 6 and separate drawing for each patient). Each patient was randomly allocated to one of the two groups of routine wound dressing (control group) or routine wound dressing + mummy (intervention group). Eight of the patients in the intervention group were not followed (four had died, four had systemic infection) seven of them in the control group were excluded from the study, (three had died four had systemic infection). Therefore 30 patients in each group, were able to finish the study. Figure 1 shows the flowchart of the study (Figure 1). This study is not double blind. Patients were randomly divided into two groups. Members of the control group were treated with normal saline and routine wound dressing. While in the intervention group, in addition to normal saline and routine wound dressing, 20\% (the saturated percent) mummy dissolution was used as well. Wound dressing was performed every morning by the same trained nurse. In the present study, $20 \%$ dissolution was used since according to the experiments, after dissolving $20 \mathrm{~g}$ mummy in $100 \mathrm{ml}$ serum, the solution will be saturated.

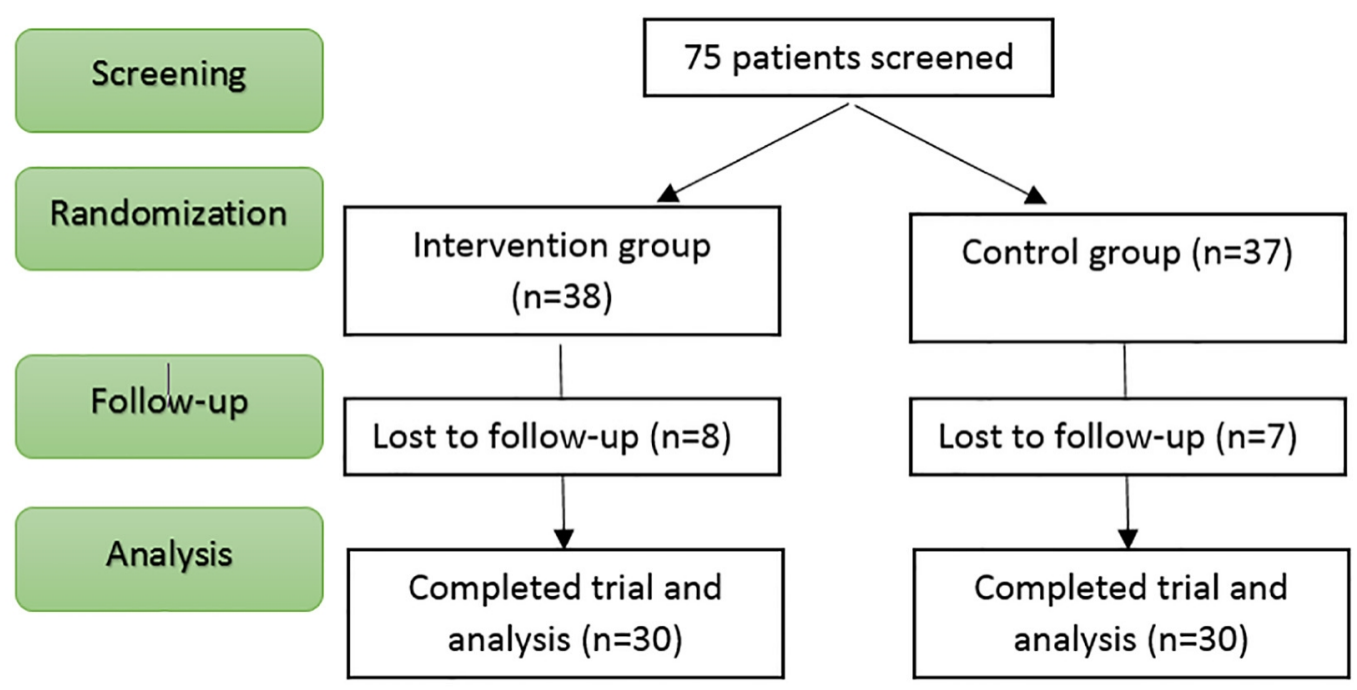

Figure 1. CONSORT Flowchart of the study

\subsection{Measurement tool}

On days $0,7,14,21$ and 28 of the treatment, the process of ulcer healing was evaluated in the two groups according to Pressure Ulcer Scale for Healing (PUSH), version 3 (14). Its total score was calculated as the sum of three subscores (i.e. wound surface area, exudate amount and tissue type) as shown in Table 1 . The wound surface area is calculated by multiplying the wound length (its longest section from top to bottom) by the wound width (its widest section from right to left). The amount of exudate was recorded after removing the previous dressing and before new therapeutic intervention. Therefore, PUSH Total Score ranges were between 0 (completely healed wound) and 17 (the most severely unimproved wound). A physician who was uninformed about the patients was elected to evaluate pressure ulcer every day at 9:00 AM. 
Table 1. Protocol of Pressure Ulcer Scale for Healing tool, version 3 (PUSH Tool 3)

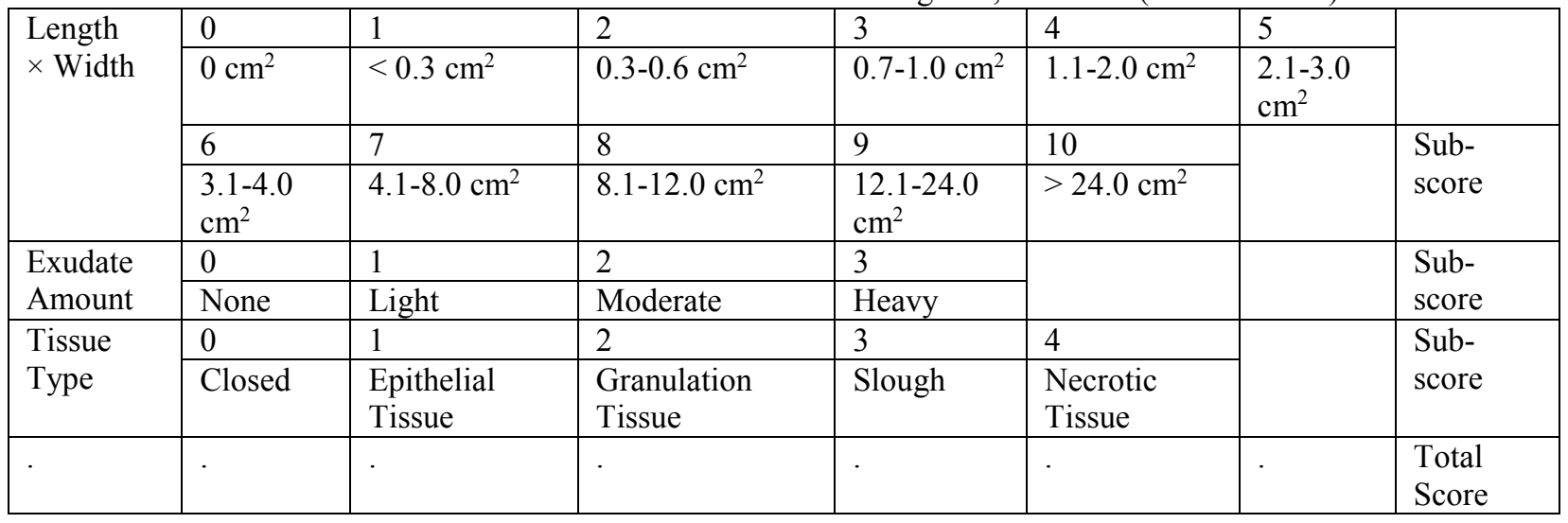

\subsection{Statistical analysis}

In order to study the effect of intervention over time, two-way repeated measurements of ANOVA were used. T-test, Cox Regression and Chi-square tests were also used through SPSS21 software. P-value $<0.05$ was considered as statistically significant.

\section{Results}

All patients were male and there was no significant difference in mean age between the intervention group (49.7 \pm 22.1 years) and the control group $(41.4 \pm 21.5$ years). The highest frequency of primary diagnosis was subdural hemorrhage SDH (15\%), followed by brain tumor BT (11.6\%). Among causes of referring, accident (61.7\%) had the highest frequency.

\subsection{Outcome 1 (Ulcer surface area)}

Mean ulcer surface area was $4 \pm 1.25 \mathrm{~cm}^{2}$ in the intervention group and $5.1 \pm 1.29 \mathrm{~cm}^{2}$ in the control group on day 0 $(\mathrm{p}<0.05)$. Therefore, this variable was considered as the confounding variable. In order to investigate the effect of time and comparing the groups, frequent measurement analysis of variance was used. According to Figure 2, the mean ulcer surface area decreased on days $0,7,14,21$ and 28 with the time, but it was more prominent in the intervention group $(\mathrm{p}<0.05)$. Mean ulcer surface area decreased from 4 to 0.53 in the intervention group and from 5.1 to 3.46 in the control group (Figure 2). In order to determine the effect of time and compare the two groups, analysis of the variance of repeated data was used. The groups showed significant difference in ulcer surface area on days 7, 14, 21 and $28(\mathrm{p}<0.01)$. In the intervention group, significant difference of ulcer surface area was observed during the experiment $(\mathrm{p}<0.001)$, but in the control group, there was a difference only on day 28 of the experiment $(\mathrm{p}<0.01)$ (Table 2).

Table 2. Comparing the effects of variables in two groups in days 7, 14, 21, and 28

\begin{tabular}{|c|c|c|c|c|c|c|c|c|c|c|}
\hline \multirow[t]{3}{*}{ Group } & \multirow[t]{3}{*}{ day } & \multirow[t]{3}{*}{ day } & \multicolumn{8}{|l|}{ Variable } \\
\hline & & & \multicolumn{2}{|l|}{ Wound are } & \multicolumn{2}{|l|}{ Exudate } & \multicolumn{2}{|c|}{ Tissue type } & \multicolumn{2}{|l|}{ Sum } \\
\hline & & & $\begin{array}{l}\text { Mean } \\
\text { Deference }\end{array}$ & $\begin{array}{l}\mathrm{p}- \\
\text { value }\end{array}$ & $\begin{array}{l}\text { Mean } \\
\text { Deference }\end{array}$ & $\begin{array}{l}\mathrm{p}- \\
\text { value }\end{array}$ & $\begin{array}{l}\text { Mean } \\
\text { Deference }\end{array}$ & $\begin{array}{l}\mathrm{p}- \\
\text { value }\end{array}$ & $\begin{array}{l}\text { Mean } \\
\text { Deference }\end{array}$ & $\begin{array}{l}\mathrm{p}- \\
\text { value }\end{array}$ \\
\hline \multirow[t]{6}{*}{ Intervention } & \multirow[t]{3}{*}{7} & 14 & 1.24 & 0.001 & 0.54 & 0.005 & 0.72 & 0.001 & 2.5 & 0.001 \\
\hline & & 21 & 2.30 & 0.001 & 0.97 & 0.001 & 1.1 & 0.001 & 4.33 & 0.001 \\
\hline & & 28 & 2.96 & 0.001 & 1.09 & 0.001 & 1.23 & 0.001 & 5.33 & 0.001 \\
\hline & \multirow[t]{2}{*}{14} & 21 & 0.96 & 0.001 & 0.43 & 0.001 & 0.38 & 0.004 & 1.84 & 0.001 \\
\hline & & 28 & 1.62 & 0.001 & 0.55 & 0.001 & 0.5 & 0.010 & 2.74 & 0.001 \\
\hline & 21 & 28 & 0.65 & 0.002 & 0.12 & 0.999 & 0.128 & 0.999 & 0.89 & 0.002 \\
\hline \multirow[t]{6}{*}{ Control } & \multirow[t]{3}{*}{7} & 14 & 0.395 & 0.374 & 0.05 & 0.999 & 0.12 & 0.999 & 0.44 & 0.999 \\
\hline & & 21 & 0.76 & 0.074 & 0.32 & 0.240 & 0.26 & 0.5 & 1.40 & 0.070 \\
\hline & & 28 & 1.44 & 0.001 & 0.67 & 0.001 & 0.77 & 0.001 & 2.90 & 0.001 \\
\hline & \multirow[t]{2}{*}{14} & 21 & 0.365 & 0.387 & 0.26 & 0.079 & 0.38 & 0.003 & 0.95 & 0.020 \\
\hline & & 28 & 1.012 & 0.003 & 0.61 & 0.001 & 0.89 & 0.001 & 0.44 & 0.001 \\
\hline & 21 & 28 & 0.646 & 0.002 & 0.3 & 0.003 & 0.5 & 0.001 & 1.50 & 0.001 \\
\hline
\end{tabular}




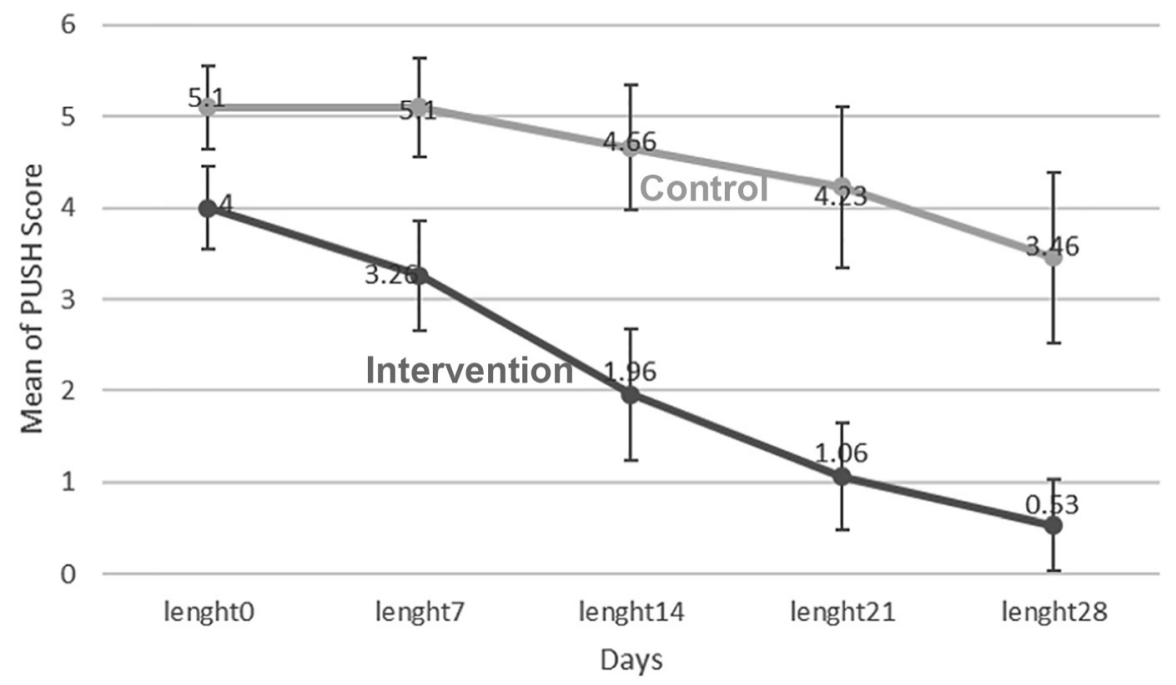

Figure 2. Mean ulcer surface area in intervention and control groups during the time

\subsection{Outcome 2 (Exudate amount)}

The two groups showed significant difference in the variable of exudate amount as on day 0 of the study, the average exudate was observed to be $1.46 \pm 0.5$ in the intervention group and $2 \pm 0.78$ in the control group ( $<<0.05$ ). Therefore, this variable was considered as the confounding variable. In order to investigate the effect of time and comparing the groups, frequent measurement analysis of variance was used. According to Figure 3, the mean exudate decreased on days $0,7,14,21$ and 28 with the time, but it was more prominent in the intervention group $(\mathrm{p}<0.05)$. Mean exudate amount decreased from 1.46 to 0.26 in the intervention group and from 2 to 1.06 in the control group (Figure 3). In the intervention group, only days 21 and 28 had non-significant difference in regard to the amount of exudate, while the differences of all other days were significant. But in the control group, only day 28 showed significant difference with the others. Table 2 shows descriptive data. Two groups had significant difference in terms of the exudate amount on days 7, 14, 21 and $28(\mathrm{p}<0.05)$.

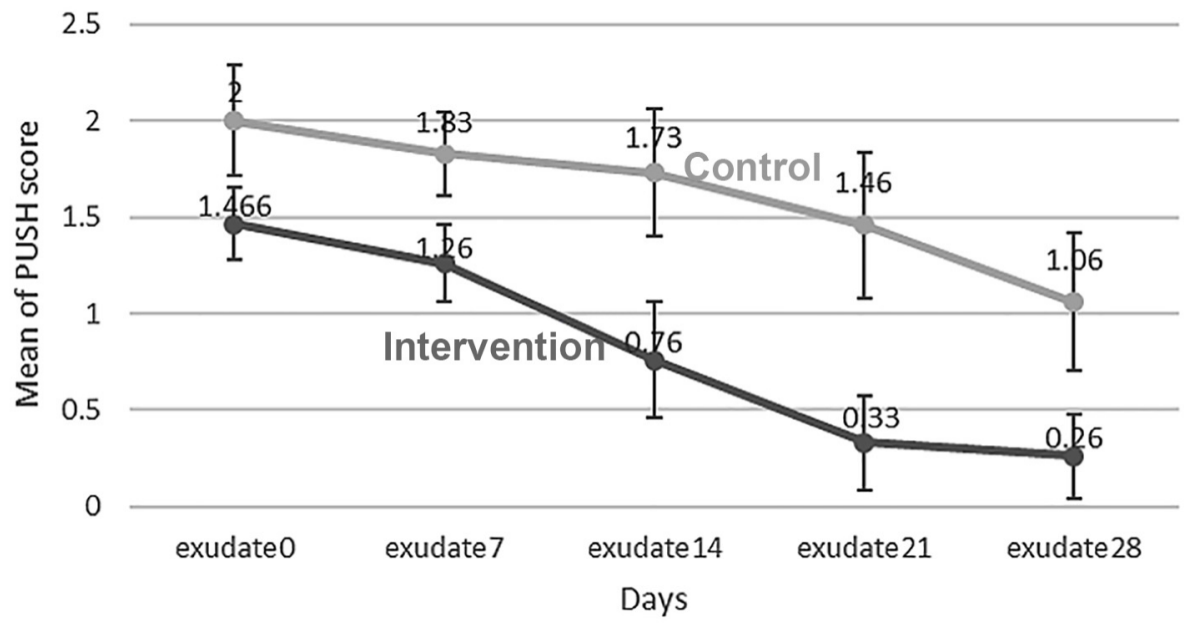

Figure 3. Mean exudate amount in the intervention and control groups during the time

\subsection{Outcome 3 (Tissue type)}

The two groups showed significant difference in the variable of tissue type on day 0 . The average tissue type was $1.8 \pm 0.66$ in the intervention group and $2.23 \pm 0.63$ in the control group $(\mathrm{p}<0.05)$. Therefore, this variable was considered as the confounding variable. In order to investigate the effect of time and comparing the groups, frequent measurement analysis of variance was used. According to Figure 4, the mean tissue type decreased on days $0,7,14$, 21 and 28 with the time, but it was more prominent in the intervention group $(\mathrm{p}<0.05)$. The average tissue type decreased from 1.36 to 0.23 in the intervention group, and from 2.13 to 1.26 in the control group. In the intervention 
group, the average tissue type decreased during the time, but in the control group, there was no change from day 7 to day 14 and the decrease was observed only after this period of time. In the intervention group, the differences of days 7,14 and 21 varied a lot in terms of the average tissue type, and that showed continuous decrease during the time. In the intervention group, only the difference of days 21 and 28 were not significant. In the control group, day 28 showed significant difference with all other days and day 14 had significant difference with day 21 in regard to the type of tissue (Table 2).

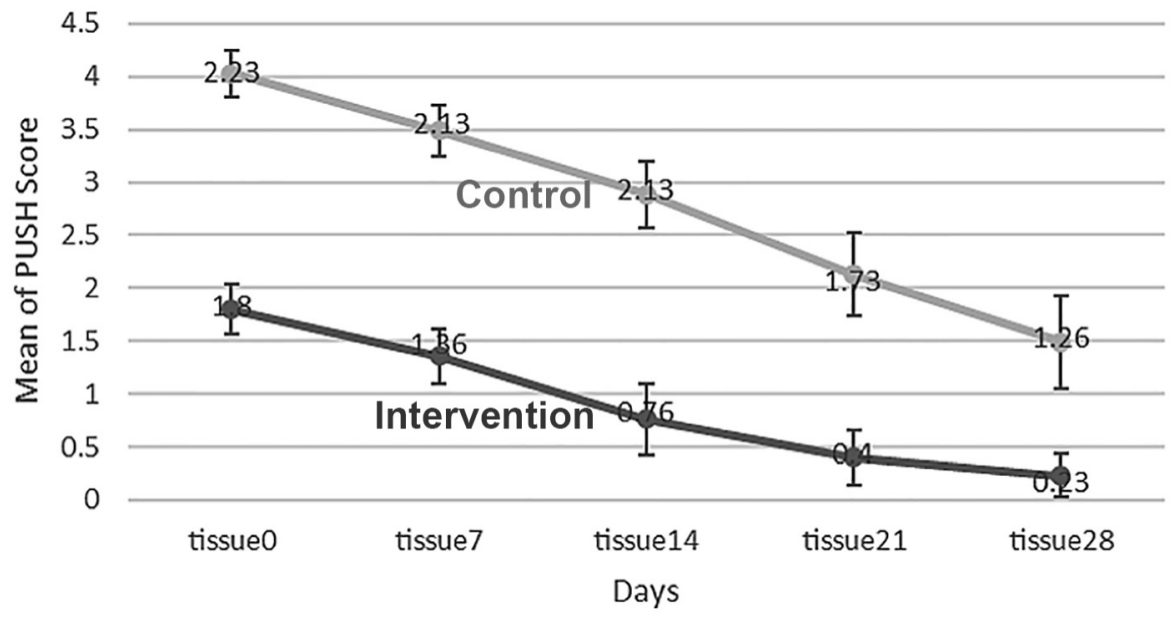

Figure 4. Mean tissue type in the intervention and control groups during the time

\subsection{Outcome 4 (The total mean)}

The groups showed significant difference in terms of total mean of the three variables (ulcer surface area, tissue type and exudate amount). On day 0 of the study, the total mean was $7.26 \pm 1.89$ in the intervention group and $9.33 \pm 2.12$ in the control group $(p<0.05)$. Therefore, this variable was considered as the confounding variable. In order to investigate the effect of time and comparing the groups, frequent measurement analysis of variance was used. According to Figure 5, the total mean of variables decreased on days 0, 7, 14, 21 and 28 with the time, but it was more prominent in the intervention group $(\mathrm{p}<0.05)$. The total mean decreased from 5.9 to 1.03 in the intervention group, and from 9.06 to 5.8 in the control group. In regard to the total mean of the intervention group, all days had significant differences with each other that showed continuous change during the time. However, in the control group, there was a significant difference only between day 28 and the other days and day 14 with day 21 . The groups showed significant differences with each other among all days of the study $(p<0.05)$ (Table 2$)$. Comparison of time of recovery in the groups showed the average recovery time of 27.53 days in the control group and 21.93 days in the intervention group. This shows significant longer recovery time in the control group. The groups were compared in terms of the number of recovered patients. The percentage of unrecovered patients in the control group $(76.7 \%)$ is significantly more than that of the intervention group $(16.7 \%)$. Comparison of recovery time in the groups showed that the average recovery time of the control group (27.53 days) is significantly more than that of the intervention group (21.93 days). Cox regression was used to compare the rate of healing of the groups. Time of healing completion was evaluated in relation to the three variables (ulcer surface area, exudate amount and tissue type). The variable of status was considered to be 0 or 1 . Status value of 0 meant recovery of the patient. According to the results, the probability of sickness continuation in the intervention group was $56 \%$ lower, while this rate was 2.3 times more in the control group. 


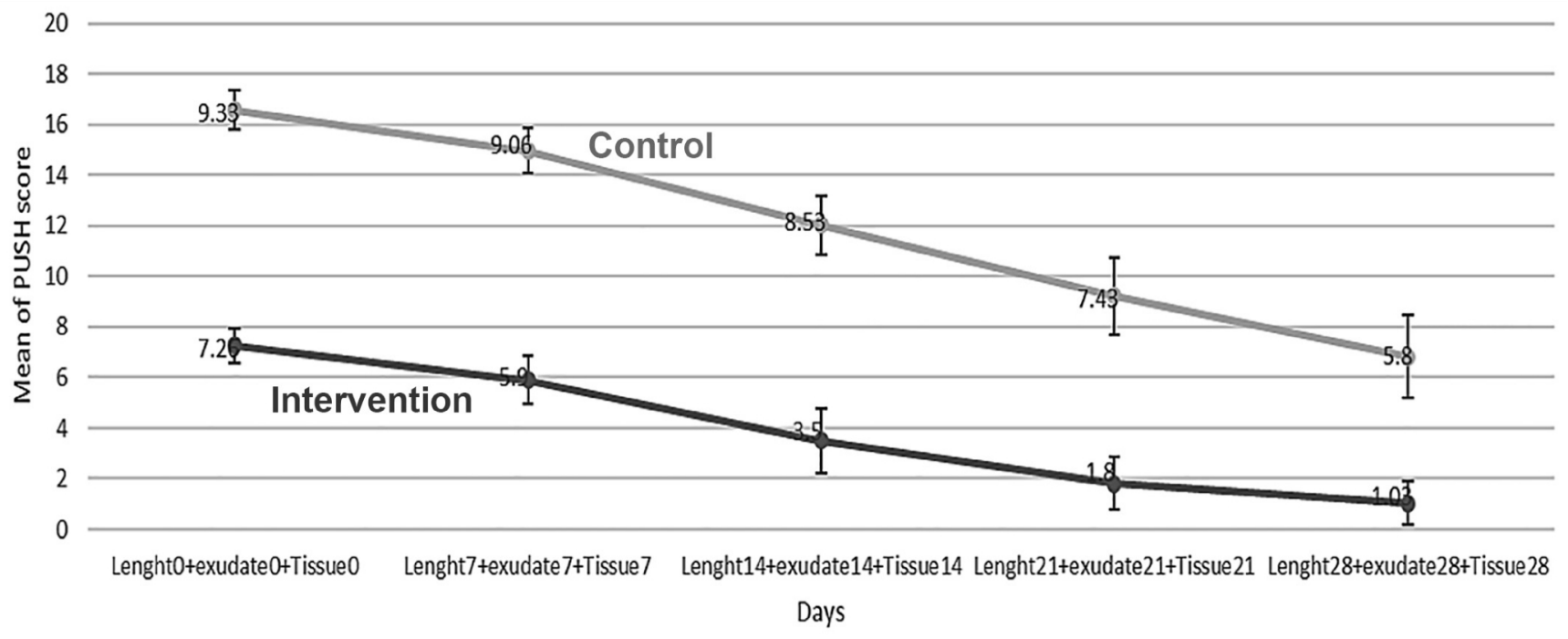

Figure 5. Total Mean of PUSH score (i.e. wound surface area, exudate amount and tissue type) groups during the time

\section{Discussion}

Although the average of all studied variables (ulcer size, exudate amount and tissue type (decreased in both groups during the time, this reduction was more significant in the intervention group than the control group. This observation shows that mummy accompanied with routine wound dressing was significantly effective in the treatment of bedsore. Tavakoli et al. performed a study on three groups of male rats. They applied mummy dissolution and phenytoin cream $10 \%$ to each one in isolation and in combination with the animals' wounds, and found that mummy accelerates wound healing and its effect is comparable with phenytoin $10 \%(15)$. Moreover, they reported that mummy has an inhibitory effect on pseudomonas growth (15). Rezvanipour et al. (2007) performed an experimental study on 56 experimental mice and compared the intervention and control groups in regard to the average of required stretch for tearing a healed ulcer and the results showed significant effect of mummy in the process of ulcer healing. In the mentioned study, the average recovery time in the intervention group ( 21.93 days) was significantly lower than that of the control group (27.53 days) (16). In an Azimian et al. study (2009), the effect of high pressure $\mathrm{O} 2$ on healing of pressure ulcer was $32 \%$ in the control group and $2 \%$ in the intervention group (17). In an Azarbarg et al. study, high pressure $\mathrm{O} 2$ caused complete ulcer healing in $75 \%$ of patients (18). In a study by Azari et al. (2011), study on five healthy white rabbits showed beneficial effects of mummy on healing of skin ulcers (19). Dehghani et al. (2011) studied 138 patients in two groups and showed the effect of mummy on healing of tibia fracture (20). Fatemi et al. compared three therapeutic methods of nursing cares which were wet wound dressing, simple wound dressing laser and simple wound dressing ultrasound on 22 homogenous patients with pressure ulcers, and concluded that wet dressing was more effective than the two other methods (21). Investigations about mummy (shilajit) show its various properties, including antioxidant (22), anti-allergic, immunomodulatory (23), anti-inflammatory (24) and analgesic (25). The present study is the first human study on pressure ulcers, and its results confirm the results of animal studies on mummy. The small number of patients and choosing only male patients were among limitations of the present study. Moreover, mummy was used in the form of topical dressing. Similar studies with larger sample size and using mummy ointment (e.g. mummy in sesame-based oil) or oral mummy are suggested.

\section{Conclusions}

In the present study, both groups showed a decreasing trend in terms of the average ulcer size, exudate amount and tissue type during the time, but the rate of this decrease was more in the intervention group. This finding shows that routine wound dressing accompanied with mummy has a significant beneficial effect in healing of bedsores.

\section{Acknowledgments:}

This study was a part of a Ph.D. thesis supported by Kerman University of Medical Sciences. The authors would like to thank Mrs. Mahmoodi for editing this article and Kerman Neuroscience Research Center, Herbal Medicine Research Center, School of Traditional Medicine and also the Deputy of Research, Kerman University of Medical Sciences. 


\section{Conflict of Interest:}

There is no conflict of interest to be declared.

Authors' contributions:

All authors contributed to this project and article equally. All authors read and approved the final manuscript.

\section{References:}

1) Berton B, Berton M. The management and prevention of pressure sore. londan berandfaber. 2001; 4: 16-21.

2) Fleck CA. Pressure ulcers risks causes, and prevention Extended Care Product News. 2005; 105: 32-40.

3) Uzun O, Aylaz R, Karadağ E. prospective study: reducing pressure ulcers in intensive care units at a Turkish medical center. J Wound Ostomy Continence Nurs. 2009; 36(4): 404-11. doi: 10.1097/WON.0b013e3181aaf524. PMID: 19609161.

4) Filius A, Damen TH, Schuijer-Maaskant KP, Polinder S, Hovius SE, Walbeehm ET. Cost analysis of surgically treated pressure sores stage III and IV. J Plast Reconstr Aesthet Surg. 2013; 66(11): 1580-6. doi: 10.1016/j.bjps.2013.05.014. PMID: 23759717.

5) Hunter SM, Cathcart-Silberberg T, Langemo DK, Olson B, Hanson D, Burd C, et al. Pressure ulcer prevalence and incidence in rehabilitation in hospital. Rehabil Nurs. 1999; 17(5): 239-42. doi: 10.1002/j.2048-7940.1992.tb01557.x. PMID: 1448603.

6) Fatemi MJ. pressure ulcer. Tehran: Nashre Chapar; 2015.

7) Aghili M. Mkhzan ol advieh. Tehran: Tehran University of Medical Sciences; 2010.

8) Ghosal S. Shilajit in Perspective. New Delhi India: Narosa Publishing House; 2006.

9) Tajadini H, Moghaderi M, Mehrabani M, Ahmadinegad M. Mummy (Shilajit) In Traditional Persian Medicine. International Journal of Biotechnology and Research. 2017; 8(2): 1297-301.

10) Goel RK, Banerjee RS, Acharya SB. Antiulcerogenic and antiiflammatory studies with shillajit. J Ethnopharmacol. 1990; 29(1): 95-103. doi: 10.1016/0378-8741(90)90102-Y. PMID: 2345464.

11) Acharya SB, Frotan MH, Goel RK, Tripathi SK, Das PK. Pharmacological actions of Shilajit. Ind J Expt Biol. 1988; 26(10): 775-7. PMID: 3248832.

12) Rezvanipour M, Pourzadehhosseini F, Malekpour R, Zarabi A. The Effect of Mummy on Some Indices of Wound Healing in Mice. Journal of Kerman University of Medical Sciences. 2007; 14(4): 267-77.

13) Wilson E, Rajamanickam GV, Dubey GP, Klose P, Musial F, Saha FJ, et al. Review on shilajit used in traditional Indian medicine. J Ethnopharmacol. 2011; 136(1): 1-9. doi: 10.1016/j.jep.2011.04.033. PMID: 21530631.

14) Gardner SE, Frantz RA, Berguist S, Shin CD. A prospective study of the pressre ulcer scale for healing ([PUSH). J Gerontol A Biol Sci Med Sci. 2005; 60(1): 93-7. doi: 10.1093/gerona/60.1.93. PMID: 15741289.

15) Tavakoli MA, Khaksari MH, Asar SK. Comparison of using topical mummy and phenytoin creams on skin wound healing of rats. J babol University Med Sci. 2003; 5(2): 7-13.

16) Rezvani-Pour M, Khatibi H. Effects of Mummy on the fracture healing in rabbit dispatching. J Kerman Univ Med Sci. 2007; 14(4): 267-77.

17) Azimian J, Pourkhalegh E, Ansari M. Assessing the topical high pressure oxygen therapy in healing of bedsore. J Qazvin Univ Med Sci. 2010; 13(4): 63-8.

18) Edsberg LE, Brogan MS, Jaynes CD, Fries K. Topical hyperbaric oxygen and electrical stimulation: Exploring potential synergy. Ostomy Wound Manage. 2002; 48(11): 42-50. PMID: 12426451.

19) Azeri A, Khyrandysh R, Srdarmhny V, Salary A. The effect of mummy on healing skin lesions in rabbits. Journal of Sabzevar University Of Medicine. 2011; 18(3): 158-65.

20) Dehghan M, Sharifi Faradonbeh A. The effect of mummy on the healing of bone fractures. African Journal of Pharmacy and Pharmacology. 2012; 6(5): 305-30. doi: 10.5897/AJPP11.353.

21) Fatemi E. Comparing effectiveness of dressing, ultrasound and laser in healing of bedsore. Journal of Kosar Medicine. 1999; 3(4): 33-6.

22) Ghosal S, Lata S, Kumar Y, Gaur B, Misra N, Soumya L. Interaction of shilajit with biogenic free radicals. Indian Journal of Chemistry B. 1995; 34: 596-602.

23) Wang C, Wang Z, Peng A, Hou J, Xin W. Interaction between fulvic acids of different origins and active oxygen radicals. Sci China C Life Sci. 1996; 39(3): 267-75. PMID: 8760456.

24) Acharya SB, Frotan MH, Goel RK, Tripathi SK, Das PK. Pharmacological actions of shilajit. Indian J Exp Biol. 1988; 26(10): 775-7. PMID: 3248832.

25) Bhattacharya SK, Sen AP, Ghosal Sh. Effects of shilajit on biogenic free radicals. Phytotherapy Research. 1995; 9(1): 56-9. doi: 10.1002/ptr.2650090113. 